\title{
Spinal Instrumented Fusion in Combination with Botulinum Toxin Treatment for Cervical Myelopathy in Patients with Athetoid Cerebral Palsy
}

\begin{abstract}
Authors:
Takeo Furuya, MD, PhD, * Masao Koda, MD, PhD,* Tuyoshi Sakuma, MD, PhD,* Yasushi Iijima, MD,* Jyunya Saito, MD,* Mitsuhiro Kitamura, MD,* Sonoko Misawa, MD, $\mathrm{PhD}$,** Kazuhide Inage, MD, PhD,* Sumihisa Orita, MD, PhD,* Satoshi Kuwabara, MD, $\mathrm{PhD}$,** Seiji Ohtori, MD, PhD,* Masashi Yamazaki, MD, $\mathrm{PhD} * * *$
\end{abstract}

*Spine Division, Department of Orthopedic Surgery, Chiba University Graduate School of Medicine, 1-8-1 Inohana, Chuo-ku, Chiba 260-8670, Japan

**Department of Neurology, Chiba University Graduate School of Medicine, 1-8-1 Inohana, Chuo-ku, Chiba 260-8670, Japan

***Spine Division, Department of Orthopedic Surgery, University of Tsukuba, 1-1-1 Tennoudai, Tsukuba, 305-8575, Japan

Address correspondence to:

Takeo Furuya, MD, PhD

Spine Division, Department of

Orthopedic Surgery,

Chiba University Graduate School of Medicine

1-8-1 Inohana, Chuo-ku, Chiba 260-8670, Japan

Tel: $+81-43-226-2117$

Fax: +81-43-226-2116

E-mail: furuya-takeo@chiba-u.jp
E-mail addresses of each author:

Takeo Furuya, furuya-takeo@ chiba-u.jp

Masao Koda, masaokod@gmail.com

Tsuyoshi Sakuma, sack244@yahoo.co.jp

Yasushi Iijima, yi02008@yahoo.co.jp

Jyunya Saito, j_sai_to@yahoo.co.jp

Mitsuhiro Kitamura, kitamitsu13@yahoo.co.jp

Sonoko Misawa, sonoko.m@mb.infoweb.ne.jp

Kazuhide Inage, kazuhideinage@chiba-u.jp

Sumihisa Orita, sorita@chiba-u.jp

Satoshi Kuwabara, kuwabara-s@ faculty.chiba-u.j]

Seiji Ohtori, sohtori@faculty.chiba-u.jp

Masashi Yamazaki, masashiy@md.tsukuba.ac.jp 
Medical Research Archives, Vol. 4, Issue 7, November 2016

Spinal Instrumented Fusion in Combination with Botulinum Toxin Treatment

for Cervical Myelopathy in Patients with Athetoid Cerebral Palsy

\section{Abstract}

Objective. To report the surgical outcomes and the details of perioperative botulinum toxin treatment of patients with cervical myelopathy associated with athetoid cerebral palsy.

Summary of Background Data. Recently, injections of botulinum toxin have been widely used to decrease spasticity and involuntary movements associated with athetosis or dystonia. Studies focusing on the details of botulinum toxin treatment are rare.

Methods. For patients who underwent surgery with spinal instrumented fusion in combination with perioperative botulinum toxin treatment, surgical outcomes, the details of botulinum toxin treatment and perioperative complications were investigated retrospectively.

Results: Of 17 patients, 15 underwent surgery by posterior methods, and 2 underwent anterior and posterior combined procedures. The mean preoperative Japanese Orthopedic Association (JOA) score was 6.9 \pm 2.4 . At the final follow-up visit, the mean JOA score was $9.2 \pm 3.3$, and the mean recovery rate was $23 \%$. Botulinum toxin treatment suppressed involuntary neck movements in all patients. Halo vest immobilization was adapted for six patients preoperatively and for four patients postoperatively. The major complication in relation to surgery was implant failure. One patient developed mild dysphasia after an injection of botulinum toxin, but it improved after conservative therapy.

Discussion \& Conclusion: Botulinum toxin treatment was performed safely and was effective in the management of involuntary neck movements. With botulinum toxin treatment, relatively good surgical outcomes were able to be obtained even if halo vest immobilization was not used in many cases. However, a high rate of implant failures was still experienced in the postoperative period. Using relatively strong external fixation, such as halo vest immobilization, together with botulinum toxin treatment may be an option for cervical myelopathy in patients with severe involuntary neck movements.

\section{Key words:}

Cervical myelopathy

Athetoid cerebral palsy

Involuntary movement

Botulinum toxin

Surgical outcome

Complication 
Medical Research Archives, Vol. 4, Issue 7, November 2016

Spinal Instrumented Fusion in Combination with Botulinum Toxin Treatment

for Cervical Myelopathy in Patients with Athetoid Cerebral Palsy

\section{Introduction}

Athetoid cerebral palsy (CP) can cause cervical spondylosis through involuntary movements, and cervical myelopathy can occur at a relatively young age $^{2,6,10,18}$. Conservative therapy is not appropriate, and surgical treatment is often required. The major factor that makes the surgical treatment complicated is involuntary neck movements. At surgery, decompression without fusion is not recommended because of the repetitive cervical movements. Therefore, rigid instrumented fixation, bony fusion, and an adjuvant treatment for controlling the neck movements are required.

Recently, injections of botulinum toxin have been used to decrease spasticity and involuntary movements associated with athetosis or dystonia 1 8, 9, 13-15, 22-24, 26 . After 2004, perioperative botulinum toxin treatment was initiated for cervical myelopathy in patients with athetoid CP in our institute. Here, we report the surgical outcomes of patients with cervical myelopathy associated with $\mathrm{CP}$ who underwent spinal instrumented fusion in combination with an injection of botulinum toxin.

\section{Materials \& Methods}

\subsection{Patient Population}

Patients who underwent spinal instrumented fusion in combination with an injection of botulinum toxin in our institute were selected, and 17 cases were retrospectively reviewed. There was one salvage surgery among these cases (Case6 and Case14 is same patient). The number of patients included in this study was 17 (12 males, 5 females). Their mean age at the time of surgery was 55 years (range, 39-73 years). The surgical indication was severe myelopathy or progression of neurologic symptoms that made the patient's activities of daily living worse. The follow-up period was an average of 53 months (range, 2-168 months). Basically, the surgical procedure included posterior 
Medical Research Archives, Vol. 4, Issue 7, November 2016

Spinal Instrumented Fusion in Combination with Botulinum Toxin Treatment

for Cervical Myelopathy in Patients with Athetoid Cerebral Palsy

decompression followed by posterior

instrumented fusion with pedicle screws or

lateral mass screws. Halo vest

immobilization was adapted for the

patients who had rapid exacerbation of

neurologic symptoms during the

preoperative period. If involuntary neck

movements were severe, an intramuscular injection of botulinum toxin was given before and/or after surgery. Halo vest immobilization was also adapted for the patients in the postoperative period when it was difficult to control the involuntary movements by botulinum toxin treatment only. A summary of the clinical data for the 17 study cases is shown in Table 1 .

Table 1. Summary of clinical data for the 17 study cases

\begin{tabular}{lc}
\hline $\begin{array}{l}\text { Sex }[\mathrm{n}] \\
\text { Male }\end{array}$ & 12 \\
Female & 5 \\
\hline Age at surgery [years] $*$ & $55(39-73)$ \\
\hline Duration of symptoms [months] $*$ & $22(2-96)$ \\
\hline Follow-up period [months]* & $53(2-168)$ \\
\hline Surgical Procedure & 15 \\
PDF & 1 \\
PDF+ multi level ACDF & 1 \\
PF+ADF & \\
\hline
\end{tabular}

PDF indicates posterior decompression with instrumented fusion;

ACDF indicates anterior cervical discectomy and fusion;

PF indicates posterior fixation;

ADF indicates anterior decompression with fusion.

*Values are expressed as the mean, with the range in parentheses.

\subsection{Surgical Strategy for Cervical}

Myelopathy in Patients with CP in Our

\section{Institute}

In our institute, laminoplasty was chosen for patients who had small involuntary movements and no evidence of instability of their cervical spine. Posterior decompression with instrumented fusion was a standard surgical procedure for 
Medical Research Archives, Vol. 4, Issue 7, November 2016

Spinal Instrumented Fusion in Combination with Botulinum Toxin Treatment

for Cervical Myelopathy in Patients with Athetoid Cerebral Palsy

patients who had involuntary movements and had evidence of instability. Levels of decompression were determined according to the neurological examination and radiographic findings. To cover a range of decompression, a range of instrumented fusion was determined. Anterior fixation and/or decompression was added to the surgical plan when the sagittal balance of the neck shifted forward or the spinal decompression was considered insufficient with the posterior method only because of the severe local kyphosis. Such cases needed stabilization of the anterior spinal column and/or decompression from the anterior approach.

\subsection{Perioperative Injection of} Botulinum Toxin in Patients with CP in Our Institute

Botulinum toxin treatment was used to decrease spasticity and involuntary movements. An injection of botulinum toxin was given in the outpatient clinic by a neurologist. The injection site and dose were determined after evaluation of the patients and their electromyogram findings. An injection was given selectively to muscles with strong tone. Because it took some time for the injection to produce an effect, the injection was generally administered prior to the surgery. A postoperative injection was given to patients with severe involuntary movements or to patients who requested it.

\subsection{Clinical Assessment}

Details of botulinum toxin treatment were examined retrospectively. The magnitude of athetoid tone was assessed by a scale reported by Mihara et al. ${ }^{20} \mathrm{~A}$ higher number corresponds to more severe movements (from grade 1 to 5). The Japanese Orthopedic Association scoring system (JOA score) was used to evaluate the patient's neurological status before surgery and at a final follow-up visit, and Hirabayashi's method ${ }^{12}$ was used to calculate the recovery rate. Details of the JOA scoring system and recovery rate are found in our previous report ${ }^{19}$. Complications related to surgery, 
Medical Research Archives, Vol. 4, Issue 7, November 2016

Spinal Instrumented Fusion in Combination with Botulinum Toxin Treatment

for Cervical Myelopathy in Patients with Athetoid Cerebral Palsy

botulinum toxin, and halo vest

immobilization were also provided.

\section{Results}

Key characteristics and clinical results of the 17 study cases are summarized in Table 2. Fifteen patients underwent posterior decompression with instrumented fusion. The remaining two patients underwent anterior and posterior combined fixation. The mean preoperative JOA score was $6.9 \pm 2.4$. At the final follow-up visit, the mean JOA score was $9.2 \pm 3.3$, and the mean recovery rate was 23\%. Botulinum toxin treatment was started during the preoperative period in 13 patients. Details of injections during the preoperative period are shown in Table 3 . Injections were started an average of 39 days (range, 5-126 days) prior to surgery. Preoperative injections of botulinum toxin were administered once in six patients, twice in six patients, and three times in one patient. For the first injection, the patient was given the maximum of 100 units.
Supplemental injections were given to the patients who had severe involuntary movements. Sternocleidomastoid, scalenus, and platysma muscles were chosen as the target flexor muscles of the neck. Splenius capitis, trapezius, levator scapulae and iliocostalis thoracis muscles were chosen as the target extensor muscles of the neck. The head-supporting muscle, the splenius capitis muscle, was chosen as needed. The timing, the site, and the dose of administration were determined according to the posture and muscle tone of the individual patient. Botulinum toxin treatment suppressed involuntary neck movements in all patients. Five out of these 13 cases that received preoperative injections continued the treatment during the postoperative period, and in four patients, injections were started postoperatively (Table 2). Details of injections during the postoperative period are shown in Table 4. The injections were continued in three patients at their request. The total dose of each injection per clinic 
Medical Research Archives, Vol. 4, Issue 7, November 2016

Spinal Instrumented Fusion in Combination with Botulinum Toxin Treatment

for Cervical Myelopathy in Patients with Athetoid Cerebral Palsy

visit was 100 units in most cases.

Halo vest immobilization was adapted for six cases in the preoperative period and for four cases in the postoperative period (Table 2).

Perioperative complications for the 17 study cases are shown in Table 5 . Complications in relation to surgery were implant failures, C5 palsy, disuse syndrome and delirium. One patient developed mild dysphasia after the injection, but it improved with conservative therapy. Complications in relation to halo vest immobilization were respiratory disorder, dysphagia, C5 palsy, appetite loss, pin site infection and pin site irritation. A representative case (Case 5) in this study is shown in Figure 1.

Table 2. Clinical details of the 17 patients

\begin{tabular}{|c|c|c|c|c|c|c|c|c|c|}
\hline \multirow{2}{*}{ Case } & \multirow{2}{*}{$\begin{array}{c}\text { Age [years] / } \\
\text { sex }\end{array}$} & \multirow{2}{*}{$\begin{array}{c}\text { Strength of } \\
\text { athetosis } \\
\text { (Grade 1-5) }\end{array}$} & \multicolumn{2}{|c|}{ Injection of botulinum toxin } & \multicolumn{2}{|c|}{ Halo vest } & \multirow{2}{*}{$\begin{array}{c}\text { Surgical } \\
\text { method }\end{array}$} & \multicolumn{2}{|c|}{ JOA score } \\
\hline & & & preoperative & postoperative & preoperative & postoperative & & preoperative & $\begin{array}{l}\text { final follow- } \\
\text { up }\end{array}$ \\
\hline 1 & $51 / \mathrm{M}$ & 3 & + & - & + & - & PDF & 7 & 5 \\
\hline 2 & $72 / \mathrm{M}$ & 3 & + & - & - & - & PDF & 4.5 & 7.5 \\
\hline 3 & $55 / \mathrm{F}$ & 3 & + & - & - & - & $\mathrm{PF}+\mathrm{ADF}$ & 5.5 & 13.5 \\
\hline 4 & $73 / \mathrm{M}$ & 3 & + & - & - & - & PDF & 8.5 & 10.5 \\
\hline 5 & $58 / \mathrm{M}$ & 3 & + & - & - & - & PDF & 5.5 & 8.5 \\
\hline 6 & $60 / \mathrm{M}$ & 3 & + & - & - & - & PDF & 5 & 5 \\
\hline 7 & $50 / \mathrm{F}$ & 2 & + & - & - & - & $\mathrm{PDF}$ & 9.5 & 13 \\
\hline 8 & $51 / \mathrm{M}$ & 4 & + & - & - & - & PDF & 9.5 & 7.5 \\
\hline 9 & $39 / \mathrm{M}$ & 3 & + & + & - & - & PDF & 9 & 14 \\
\hline 10 & 49/M & 2 & + & + & - & - & PDF & 10.5 & 12 \\
\hline 11 & $57 / \mathrm{M}$ & 2 & + & + & - & - & PDF & 7.5 & 7.5 \\
\hline 12 & $49 / \mathrm{M}$ & 4 & + & + & + & - & PDF & 3 & 11 \\
\hline 13 & $62 / \mathrm{M}$ & 4 & + & + & - & - & PDF & 6.5 & 8.5 \\
\hline 14 & $62 / \mathrm{M}$ & 3 & - & + & + & + & $\mathrm{PDF}+\mathrm{ACDF}$ & 5 & 5 \\
\hline 15 & $54 / \mathrm{F}$ & 2 & - & + & + & + & PDF & 4 & 6 \\
\hline 16 & $41 / \mathrm{F}$ & 3 & - & + & + & + & PDF & 5.5 & 7 \\
\hline 17 & $48 / \mathrm{F}$ & 3 & - & + & + & + & PDF & 11 & 14 \\
\hline
\end{tabular}

$\mathrm{PF}$ indicates posterior fixation; ADF, anterior decompression and fusion; ACDF, anterior cervical discectomy and fusion; $\mathrm{PDF}$, posterior decompression with instrumented fusion.

JOA indicates Japanese Orthopedic Association (full score $=17$ points). 
Medical Research Archives, Vol. 4, Issue 7, November 2016

Spinal Instrumented Fusion in Combination with Botulinum Toxin Treatment for Cervical Myelopathy in Patients with Athetoid Cerebral Palsy

Table 3. Injection of botulinum toxin at preoperative period

\begin{tabular}{|c|c|c|c|c|}
\hline \multirow{2}{*}{ Case } & \multirow{2}{*}{$\begin{array}{c}\text { Time of } \\
\text { injection before } \\
\text { surgery [days] }\end{array}$} & \multirow{2}{*}{$\begin{array}{c}\text { Total dose of } \\
\text { injection [Unit] }\end{array}$} & \multicolumn{2}{|c|}{ Muscle of injection and dose [Unit] } \\
\hline & & & flexor & extensor \\
\hline 1 & 21 & 60 & $\operatorname{SCM}(60)$ & \\
\hline 2 & 14 & 60 & & $\mathrm{SC}(60)$ \\
\hline \multirow{2}{*}{3} & $66(1 \mathrm{st})$ & 100 & $\operatorname{SCM}(50)$ & $\mathrm{SC}(50)$ \\
\hline & 38 (2nd) & 100 & $\mathrm{P}(50)$ & ICT (50) \\
\hline 4 & 51 & 100 & $\operatorname{SCM}(60), S(40)$ & \\
\hline \multirow{2}{*}{5} & $67(1 \mathrm{st})$ & 100 & $\operatorname{SCM}(50)$ & $\mathrm{SC}(50)$ \\
\hline & $2(2 \mathrm{nd})$ & 60 & $S(60)$ & \\
\hline \multirow{2}{*}{6} & 35 (1st) & 100 & $\operatorname{SCM}(65)$ & $\mathrm{SC}(35)$ \\
\hline & 14 (2nd) & 200 & $\mathrm{~S}(75)$ & $\mathrm{T}(125)$ \\
\hline 7 & 15 & 50 & $\operatorname{SCM}(50)$ & \\
\hline \multirow{2}{*}{8} & $42(1 \mathrm{st})$ & 100 & $\operatorname{SCM}(50)$ & $\mathrm{SC}(50)$ \\
\hline & $7(2 \mathrm{nd})$ & 125 & $\operatorname{SCM}(25)$ & $\operatorname{IOC}(50), \mathrm{SC}(50), \operatorname{LS}(50)$ \\
\hline \multirow{2}{*}{9} & 27 (1st) & 100 & & $\mathrm{SC}(50), \mathrm{T}(50)$ \\
\hline & 9 (2nd) & 100 & $\mathrm{~S}(50)$ & $\mathrm{T}(50)$ \\
\hline 10 & 5 & 100 & $\operatorname{SCM}(75)$ & IOC (25) \\
\hline 11 & 22 & 100 & & $\mathrm{~T}(100)$ \\
\hline \multirow{2}{*}{12} & $21(1 \mathrm{st})$ & 100 & & IOC (50), SC (50) \\
\hline & 7 (2nd) & 125 & $\operatorname{SCM}(50), \mathrm{P}(25)$ & $\mathrm{SC}(50)$ \\
\hline \multirow{3}{*}{13} & $126(1 \mathrm{st})$ & 100 & $\mathrm{P}(100)$ & \\
\hline & 94 (2nd) & 60 & $P(60)$ & \\
\hline & $8(3 \mathrm{rd})$ & 225 & $\operatorname{SCM}(50)$ & $\mathrm{SC}(50), \mathrm{T}(125)$ \\
\hline
\end{tabular}

SCM indicates Sternocleidomastoid; SC, Splenius capitis; P, Platysma; ICT, Iliocostalis thoracis;

$\mathrm{S}$, Scalenus; T, Trapezius; IOC, Inferior obliquus capitis, LS, levator scapulae. 
Medical Research Archives, Vol. 4, Issue 7, November 2016 Spinal Instrumented Fusion in Combination with Botulinum Toxin Treatment for Cervical Myelopathy in Patients with Athetoid Cerebral Palsy

Table 4. Injection of botulinum toxin in the postoperative period

\begin{tabular}{cccc}
\hline Case & Frequency & $\begin{array}{c}\text { Time of } \\
\text { injection after } \\
\text { surgery [Days] }\end{array}$ & $\begin{array}{c}\text { Total dose per } \\
\text { injection [Unit] }\end{array}$ \\
\hline 9 & single & 50 & 100 \\
\hline 10 & single & 21 & 100 \\
\hline 11 & single & 45 & 100 \\
\hline 12 & every 6 months & - & 100 \\
\hline 13 & every 3 months & - & 200 \\
\hline 14 & single & 90 & 100 \\
\hline 15 & single & 31 & 100 \\
\hline 16 & every 3 months & - & $60-180$ \\
\hline 17 & 3 times & - &
\end{tabular}

Table 5. Perioperative complications for the 17 study cases

\begin{tabular}{ll}
\hline Surgery related & 6 \\
Implant failure & 2 \\
C5 palsy & 1 \\
Disuse syndrome & 1 \\
Delirium & \\
\hline Botulinum toxin treatment related & 1 \\
$\quad$ Dysphagia & \\
\hline Halo vest related & 1 \\
Respiratory disorder & 1 \\
Dysphagia & 1 \\
C5 palsy & 1 \\
Appetite loss & 1 \\
Infection of halo vest's pin & 1 \\
Irritation of halo vest's pin & 1 \\
\hline
\end{tabular}


Medical Research Archives, Vol. 4, Issue 7, November 2016

Spinal Instrumented Fusion in Combination with Botulinum Toxin Treatment

for Cervical Myelopathy in Patients with Athetoid Cerebral Palsy
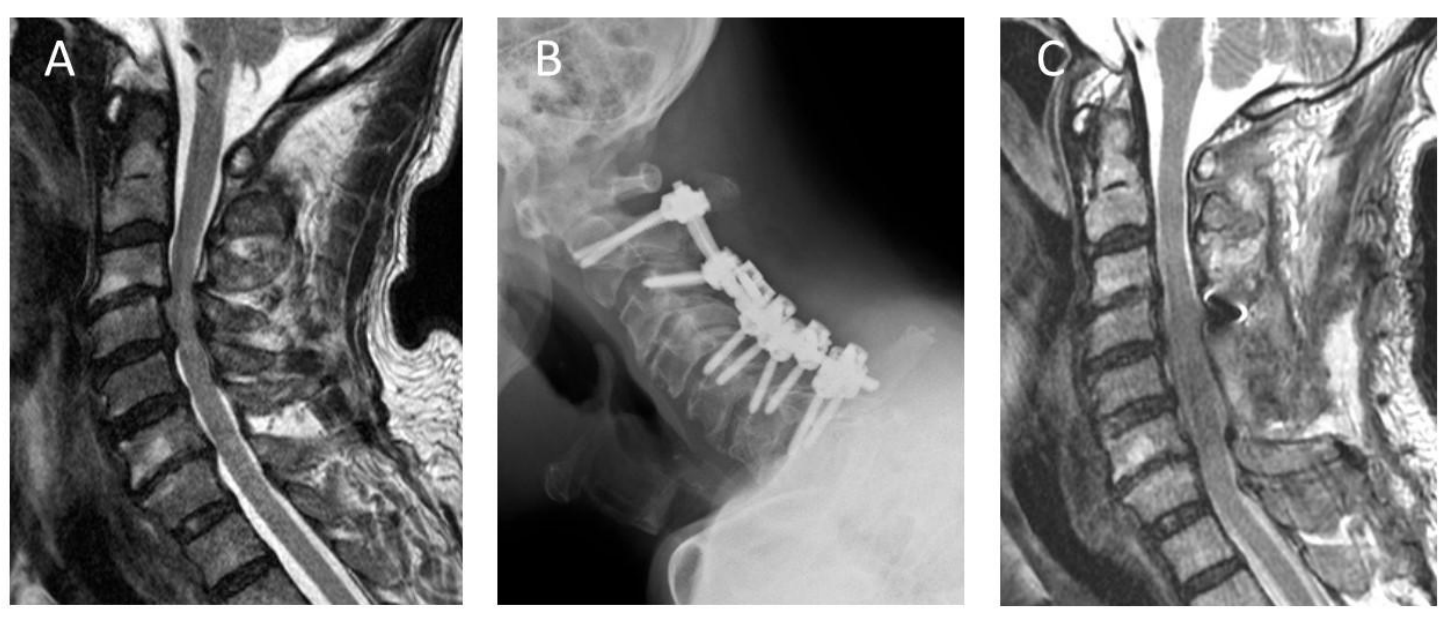

\section{Figure 1.}

\section{Figure legend}

Figure 1. Radiological images of a 58-year-old man diagnosed with cervical myelopathy because of athetoid CP (Case 5).

(A) Preoperative T-2 weighted midsagittal magnetic resonance (MR) image; (B) Postoperative lateral radiographical image in a neutral position; and (C) T-2 weighted midsagittal magnetic resonance (MR) image, 1 month after posterior decompression at C3-C6 with instrumented fusion at $\mathrm{C} 2-\mathrm{C} 7$ using pedicle screws at $\mathrm{C} 2, \mathrm{C} 5, \mathrm{C} 6$, and $\mathrm{C} 7$, and lateral mass screws at $\mathrm{C} 3$. An injection of botulinum toxin was given during the preoperative period to control his involuntary neck movements.

\section{Discussion}

\subsection{Recent Surgical Methods for}

\section{Cervical Myelopathy in Patients with CP}

Because of the strong muscle tone and involuntary movements, the treatment of cervical myelopathy in association with $\mathrm{CP}$ is more difficult than that of typical cervical spondylotic myelopathy. Surgical methods can be classified generally into anterior decompression with fusion, posterior decompression with instrumented fusion, laminoplasty, and posterior fixation and anterior combined decompression and fusion. Each method has its merits and disadvantages. The choice of the surgical method varies among cases and institutes.

The purposes of the surgery are spinal decompression and rigid fixation, 
Medical Research Archives, Vol. 4, Issue 7, November 2016

Spinal Instrumented Fusion in Combination with Botulinum Toxin Treatment

for Cervical Myelopathy in Patients with Athetoid Cerebral Palsy

whether by the anterior method or the posterior method. With regard to the range of fixation, a relatively long fixation is recommended for the sake of rigid fixation. However, the long fusion from the anterior approach is sometimes complicated, and intensive care for the associated respiratory complications is needed during the postoperative period. The risk with the posterior approach is lower than with the anterior approach in a long fusion. Some authors have reported the clinical outcomes of posterior decompression with instrumented fusion for cervical

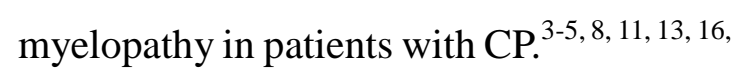
21, 26 The surgical outcome is acceptable. A rod or plate-wiring system has been the major technique for fixation in the past, but a rod-screw system has been the focus of much recent attention with the progress of this instrumentation. ${ }^{4,8,13,21,26,27}$ Lee et al reported the efficacy of correcting the deformity recently. ${ }^{16}$ They reported that patients who underwent deformity correction had better clinical and functional outcomes than patients who did not undergo deformity correction. Correction may be considered in cases of severe kyphosis; however, careful attention to the risk needs to be paid.

\subsection{Control of Involuntary}

\section{Movements}

Treatment in the perioperative period includes the following methods in order to control involuntary movements and to obtain rigid fixation until bone union occurs: halo vest immobilization, muscle release $^{25}$ or injection of botulinum toxin. The addition of a postoperative halo vest immobilization may pose additional risks of halo-related complications such as dysphagia and respiratory complications. Also, there can be the problem of the patient's psychological stress from wearing a halo vest for several months. Wearing a halo vest is difficult in cases with severe involuntary movements. An infection or irritation of the pin on the halo ring might occur. It is true that muscle release is effective in some cases; however, it is necessary to pay attention to the fact that muscle release is irreversible. Some 
Medical Research Archives, Vol. 4, Issue 7, November 2016

Spinal Instrumented Fusion in Combination with Botulinum Toxin Treatment

for Cervical Myelopathy in Patients with Athetoid Cerebral Palsy

patients with athetoid $\mathrm{CP}$ may swallow using their involuntary movements skillfully. The swallowing function might be reduced when involuntary movements are lost due to muscle release surgery.

\subsection{Botulinum Toxin Treatment}

Recently, the usefulness of botulinum therapy has been reported. $1,8,9$, 13-15, 22-24, 26 We previously reported the effectiveness of botulinum toxin treatment. $^{8} \quad$ Relatively good surgical outcomes were able to be obtained with botulinum toxin treatment even if halo vest immobilization was not used. The advantage of botulinum toxin treatment is the ability to control muscles and the dose of injection in every case. The effect of the injection dampens in approximately three months; a supplemental injection is then given if necessary. This fact seems to be a disadvantage; however, it can be viewed as an advantage since the choice of muscles and dose can be reconsidered with every injection.

Our strategy to control the involuntary neck movements is as follows. The patients with small involuntary movements, such as those who can undergo magnetic resonance (MR) imaging without sedation, do not need halo vest immobilization and botulinum toxin treatment. Botulinum toxin treatment is a first choice for the patients with relatively strong involuntary movements. Halo vest immobilization together with botulinum toxin treatment may be one of the options in patients with severe involuntary neck movements.

\subsection{Perioperative Complications}

Because of the severe involuntary movements associated with athetoid $\mathrm{CP}$, the number of perioperative complications is relatively high compared with typical cervical spondylotic myelopathy. Perioperative complications for the 17 study cases are listed in Table 5. Some of the complications are because of involuntary movements and surgery itself. $^{11,13,21}$ The others are the result of wearing a halo vest. $^{7,17,26}$ A high rate of implant failures was experienced such as 
loosening of the screws and breakage of

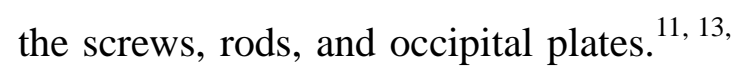
${ }^{15,21}$ Careful attentions to the patients need to be paid during the postoperative period until bone union occurs. Other important complications related to surgery and halo vest immobilization are postoperative radicular pain and upper extremity motor weakness. There is a risk that nerve-root irritation from foraminal stenosis will occur at a higher rate than in typical cervical spondylotic myelopathy when instrumented fusion or halo vest immobilization is performed. At surgery, preventive facetectomy of $\mathrm{C} 4 / 5$ bilaterally is performed if a risk of foraminal stenosis is found.

\subsection{Limitations}

This study is limited by its retrospective design and by its small sample size. The surgical procedures and the use of botulinum toxin were not homogeneous. Also, the muscle tonus pre-injection and post-injection were not compared. Finally, to prove the effectiveness of botulinum toxin injection, cases with or without an injection needed to be compared in a future study.

\section{Conclusion}

Botulinum toxin treatment was performed safely and was effective in the pre- and postoperative management of involuntary neck movements. By administering botulinum toxin treatment, relatively good surgical outcomes were able to be obtained even if halo vest immobilization was not used in many cases. However, a high rate of implant failures was still experienced in the postoperative period. Using a relatively strong external fixation, such as a halo vest, together with botulinum toxin treatment may be one of the additional therapeutic methods for cervical myelopathy in patients with severe involuntary neck movements. 
Medical Research Archives, Vol. 4, Issue 7, November 2016

Spinal Instrumented Fusion in Combination with Botulinum Toxin Treatment

for Cervical Myelopathy in Patients with Athetoid Cerebral Palsy

\section{Reference}

1. Adler $\mathrm{CH}$, Zimmerman RS, Lyons MK, et al. Perioperative use of botulinum toxin for movement disorder-induced cervical spine disease. Mov Disord 1996; 11: 79-81.

2. Anderson WW, Wise BL, Itabashi $\mathrm{HH}$, et al. Cervical spondylosis in patients with athetosis. Neurology 1962; 12: 410-2.

3. Azuma S, Seichi A, Ohnishi I, et al: Long-term results of operative treatment for cervical spondylotic myelopathy in patients with athetoid cerebral palsy. Spine 2002; 27: 943-8.

4. Demura S, Murakami H, Kawahara N, et al. Laminoplasty and pedicle screw fixation for cervical myelopathy associated with athetoid cerebral palsy. Spine 2013; 20: 1764-9.

5. Duruflé A, Pétrilli S, Le Guiet JL, et al. Cervical spondylotic myelopathy in athetoid cerebral palsy patients: about five cases. Joint Bone Spine 2005; 72: 270-4.

6. Ebara S, Yamazaki Y, Harada T, et al. Motion analysis of the cervical spine in athetoid cerebral palsy. Extension-flexion motion. Spine 1990; 15: 1097-103.
7. Epstein NE. Circumferential cervical surgery for spondylostenosis with kyphosis in two patients with athetoid cerebral palsy. Surg Neurol 1999; 52: 339-44.

8. Furuya T, Yamazaki M, Okawa A, et al. Cervical myelopathy in patients with athetoid cerebral palsy. Spine (Phila $\mathrm{Pa}$ 1976). 2013; 38: E151-7.

9. Gasser T, Fritsch $\mathrm{K}$, Arnold G, et al. Botulinum toxin A in orthopaedic surgery. Lancet 1991; 338: 761.

10. Harada T, Ebara S, Anwar MM, et al. The cervical spine in athetoid cerebral palsy: a radiological study of 180 patients. J Bone Joint Surg Br 1996; 78: 613-9.

11. Haro H, Komori H, Okawa A, et al. Surgical treatment of cervical spondylotic myelopathy associated with athetoid cerebral palsy. J Orthop Sci 2002; 7: 629-36.

12. Hirabayashi K, Miyakawa J, Satomi K, et al. Operative results and postoperative progression of ossification among patients with ossification of cervical posterior longitudinal ligament. Spine 1981; 6: 354-64. 
Medical Research Archives, Vol. 4, Issue 7, November 2016

Spinal Instrumented Fusion in Combination with Botulinum Toxin Treatment

for Cervical Myelopathy in Patients with Athetoid Cerebral Palsy

13. Jameson R, Rech C, Garreau de Loubresse C. Cervical myelopathy in athetoid and dystonic cerebral palsy: retrospective study and literature review. Eur Spine J 2010; 19: 706-12.

14. Jankovic J, Schwartz PA. Botulinum toxin injections for cervical dystonia. Neurology 1990; 40: 277-80.

15. Kim KN, Ahn PG, Ryu MJ, et al. Long-term surgical outcomes of cervical myelopathy with athetoid cerebral palsy. Eur Spine J. 2014; 23:1464-71.

16. Lee CK, Ha Y, Cho SR, et al. Clinical outcomes of correcting cervical deformity in cerebral palsy patients. World Neurosurg. 2016 [Epub ahead of print].

17. Lee YJ, Chung DS, Kim JT, et al. Surgical treatments for cervical spondylotic myelopathy associated with athetoid cerebral palsy. J Korean Neurosurg Soc 2008; 43: 294-9.

18. Levine RA, Rosenbaum AE, Waltz JM, et al. Cervical spondylosis and dyskinesias. Neurology 1970; 20: 1194-9.

19. Masaki Y, Yamazaki M, Okawa A, et al. An analysis of factors causing poor surgical outcome in patients with cervical myelopathy due to ossification of the posterior longitudinal ligament: anterior decompression with spinal fusion versus laminoplasty. J Spinal Disord Tech 2007; 20: 7-13.

20. Mihara H, Kondo S, Kohno $\mathrm{M}$, et al. Clinical analysis of reoperation following surgical treatments for cervical spondylotic myelopathy accompanied with athetoid cerebral palsy. Rynsho Seikeigeka 2008; 43: 465-72 (Japanese).

21. Miyamoto $\mathrm{H}$, Uno $\mathrm{K}$, Inui $\mathrm{Y}$, et al. Indications and limitations of posterior reconstruction surgery for 100 cases of non-traumatic disorders in the middle and the lower cervical spine. J Japanese Society Spine Surg Relat Res 2009; 20: 755-60.

22. Priori A, Berardelli A, Mercuri B, et al. Physiological effects produced by botulinum toxin treatment of upper limb dystonia. Changes in reciprocal inhibition between forearm muscles. Brain 1995; 118: 801-7.

23. Racette BA, Lauryssen C, Perlmutter JS. Preoperative treatment with botulinum toxin to facilitate cervical fusion in dystonic cerebral palsy. Report of two cases. J Neurosurg 1998; 88: 328-30. 
Medical Research Archives, Vol. 4, Issue 7, November 2016

Spinal Instrumented Fusion in Combination with Botulinum Toxin Treatment for Cervical Myelopathy in Patients with Athetoid Cerebral Palsy

24. Traynelis VC, Ryken T, Rodnitzky RL, et al. Botulinum toxin enhancement of postoperative immobilization in patients with cervical dystonia. Technical note. Neurosurg 1992; 77: 808-9.

25. Ueda Y, Yoshikawa T, Koizumi M, et al. Cervical laminoplasty combined with muscle release in patients with athetoid cerebral palsy. Spine 2005; 30: 2420-3.

26. Wong AS, Massicotte EM, Fehlings MG. Surgical treatment of cervical myeloradiculopathy associated with movement disorders: indications, technique, and clinical outcome. J Spinal Disord Tech 2005; 18 Suppl: S107-14.

27. Zhou H, Liu ZJ, Wang SB, et al. Laminoplasty with lateral mass screw fixation for cervical spondylotic myelopathy in patients with athetoid cerebral palsy: A retrospective study. Medicine (Baltimore). 2016; 95: e5033. 